\title{
Molecular analysis of hearing loss associated with enlarged vestibular aqueduct in the mainland Chinese: a unique SLC26A4 mutation spectrum
}

\author{
Hao Hu · Lingqian Wu Y Yong Feng • Qian Pan • \\ Zhigao Long · Juan Li $\cdot$ Heping Dai $\cdot$ Kun Xia · \\ Desheng Liang $\cdot$ Norio Niikawa $\cdot$ Jiahui Xia
}

Received: 2 February 2007 / Accepted: 11 March 2007/Published online: 19 April 2007

(C) The Japan Society of Human Genetics and Springer 2007

\begin{abstract}
It has been shown that mutations in the SLC26A4 gene are involved in syndromic deafness characterized by congenital sensorineural hearing impairment and goitre (Pendred's syndrome), as well as in congenital isolated deafness (DFNB4), both of which are associated with enlarged vestibular aqueduct (EVA). The prevalence of SLC26A4 mutations in Pendred's syndrome is clearly established in many ethnic groups, but the data from Mainland Chinese patients with deafness and EVA remain poor. In this report, 15 patients from 13 unrelated Chinese families with deafness and EVA were analyzed for SLC26A4 using direct sequencing. A total of 15 pathogenic mutations were observed in 11 unrelated families, 4 of which were novel. One mutation, IVS7-2A $>$ G, was most common, accounting for $22.3 \%(5 / 22)$ of all the mutant
\end{abstract}

Hao $\mathrm{Hu}$, Lingqian $\mathrm{Wu}$, Yong Feng have contributed equally to this work. The authors of this manuscript declare that they have no competing interests.

H. Hu $\cdot$ L. Wu $\cdot$ Q. Pan $\cdot$ Z. Long $\cdot$ J. Li $\cdot$ H. Dai

K. Xia $\cdot$ D. Liang $(\bowtie) \cdot$ J. Xia

National Laboratory of Medical Genetics, Xiangya Hospital,

Central South University, 110 Xiangya Road, Changsha,

Hunan 410078, China

e-mail: liangdesheng@cnlmg.com

Y. Feng

Department of Otorhinolaryngology, Xiangya Hospital, Central South University, Changsha, China

L. Wu $\cdot$ D. Liang $\cdot$ N. Niikawa

Department of Human Genetics, Nagasaki University Graduate

School of Biomedical Sciences, Nagasaki, Japan

L. Wu $\cdot$ D. Liang $\cdot$ N. Niikawa

Solution Oriented Research of Science and Technology (SORST), Japan Science and Technology Agency (JST),

Kawaguchi, Japan alleles, and H723R was infrequent. To date, a total of 23 mutations have been reported among the Chinese, 13 of which were unique. In conclusion, EVA could be a radiological marker for $S L C 26 A 4$ analysis among Mainland Chinese hearing-loss patients, and the SLC26A4 mutation spectrum in the Chinese was different from other reported populations.

Keywords Enlarged vestibular aqueduct - Molecular analysis $\cdot$ SLC26A4 mutations - Chinese

\section{Introduction}

Profound hearing loss affects one in 1000 newborns, and about a half of cases are attributed to genetic factors in western countries (Morton 1991). To date, over 100 nonsyndromic hearing loss (NSHL) loci have been mapped, and 41 genes responsible for NSHL have been identified (Van Camp 2006). Among them, the gap junction protein beta $2(G J B 2)$ gene plays a major role in the occurrence of autosomal recessive NSHL, and its mutated protein accounts for up to half of NSHL in some ethnic populations (Kenneson et al. 2002). Mutations in mtDNA could be another important cause of NSHL (Fischel-Ghodsian 1999; Guan 2004) and the incidence of its A1555G mutation is $\sim 2.9 \%$ among the Chinese pediatric population with NSHL (Li et al. 2005).

Homozygous mutations in the SLC26A4 gene cause Pendred's syndrome (PS, OMIM 274600) characterized by sensorineural hearing loss and goiter (Everett et al. 1997), or DFNB4 (OMIM 600791), as well as another automsomal recessive non-syndromic hearing loss without goiter (Li et al. 1998). Taken together, DFNB4 and PS are estimated to account for 5-10\% of congenital hearing loss, and 
hearing loss in both disorders is prelingual (Reardon et al. 1999) and frequently associated with enlarged vestibular aqueduct (EVA). Much work has revealed the relationship between EVA and SLC26A4 mutations (Everett et al. 1997; Coyle et al. 1998; Campbell et al. 2001; Yong et al. 2001; Park et al. 2003). A finding in the murine that Foxil is a gene regulator of pendrin suggests that human FOXII could be another gene causative for human hearing loss with EVA (Hulander et al. 2003), but no causative mutation of FOXII was revealed among EVA patients without SLC26A4 mutations. To date, more than 100 SLC26A4 mutations spanning the entire coding region have been described (http://www.medicine.uiowa.edu/pendredandbor/listed_mutations.htm), and 13 of them were observed in the Chinese (Yong et al. 2001; Park et al. 2003; Hu et al. 2005a; Wu et al. 2005; Yang et al. 2005). Previous studies revealed different ethnic groups have unique mutation spectra (Coyle et al. 1998; Campbell et al. 2001; Tsukamoto et al. 2003; Wu et al. 2005). In the Chinese, IVS7$2 \mathrm{~A}>\mathrm{G}$ was most common, accounting for $84 \%$ of mutations (Wu et al. 2005). Most of the published work dealt with Chinese patients in Taiwan and Singapore, but data from the mainland of China have still been poor.

To know the distribution and frequencies of SLC26A4 mutations in mainland Chinese, we investigated in this study a total of 15 patients with hearing loss and with EVA from 13 Chinese families, among which the GJB2, mtDNA 12s rRNA and the FOXII were also screened.

\section{Subjects and methods}

\section{Subject selection}

Fifteen prelingual hearing-loss patients (from 13 unrelated families) with an age range of 2-23 years, and some of their family members, were enrolled. One hundred randomly selected normal-hearing individuals were also included. Informed consent was obtained from all these participants prior to the study, in accordance with the Institutional Review Board and Ethical Committee of Xiangya Hospital of Central South University. Two (DF003 and DF008) of the 15 patients were those reported previously (Hu et al. 2005a, b). Two families were multiplex. In one family (NDF6) where parents were consanguineous, only the proband (a daughter, DF007) was assessed. All the 13 families come from the Central South Area of China. Comprehensive family history was taken, especially with regard to the previous use of aminoglycosides or other drugs, any diseases and their treatments, the age of onset, and any possible genetic factors related to their hearing loss. EVA was defined here when enlargement of the vestibular aqueduct was $>1.5 \mathrm{~mm}$ at midway between the endolymphatic sac and the vestibule. Perchlorate discharge test was not performed on the patients.

Age-appropriate audiological examinations were performed, which included pure-tone audiometry (PTA), immittance testing and transiently evoked otoacoustic emissions (TEOAE). If PTA was unavailable for young patients, auditory brainstem response (ABR) was done. PTA was calculated from the sum of audiometric thresholds at 500, 1,000, and 2,000 Hz. The severity of hearing loss was classified into the following five grades: (a) mild (20-39 dB), (b)moderate (40-54 dB), (c) moderate severe (55-69 dB), (d) severe (70-90 dB), and (5) profound hearing-loss $(>90 \mathrm{~dB})$. Hearing loss was considered as "progressive" when the patients lost more than $8 \mathrm{~dB}$ in the PTA thresholds when comparing two reliable audiometric tests carried out at least 5 years apart, and as "fluctuant" when the mean hearing level had risen by more than $10 \mathrm{~dB}$ between two successive audiograms.

\section{Mutation screening}

Genomic DNA was extracted from peripheral blood leukocytes with the standard procedures. Polymerase chain reaction (PCR) amplification of all 21 exons of the SLC26A4 gene was performed as described previously (Everett et al. 1997; Coyle et al. 1998; Prasad et al. 2004; $\mathrm{Hu}$ et al. 2005a), and PCR products were directly sequenced after removal of unincorporated dNTPs and primers. Sequencing results were analyzed using the DNASTAR $^{\mathrm{TM}}$ software program package (DNASTAR Inc., WI, USA). The data were subsequently compared with the wild-type SLC26A4 sequence in Genbank [accession number: NT_007933 (gDNA), NM_000441 (cDNA)]. All samples were also screened for mutation in the GJB2 gene, and for the $\mathrm{A} 1555 \mathrm{G}$ mutation in mtDNA as previously described ( $\mathrm{Li}$ et al. 2004; $\mathrm{Hu}$ et al. 2005b). FOXI1 gene was screened using the following primers, which were designed for 2 exons including their flanking intronic sequences (sequence accession number: NM_012188): FX1AF: 5'-GCCAAGCCCTAGGGGTAT AA-3', FX1AR: 5'-AGCTTCATCAGCTCCTCCTG-3', FX1BF: 5'-CAACCCCTACCTCTGGTTCA-3', FX1BR: 5'-GGGAGGAAGGAAGTGAGTC-3', FX2AF: 5'-TTCC TGCATCTGTCACCTTG-3', FX2AR: 5'-CTCAGTCCTG GTGTGACCAA-3', FX2BF: 5'-CATCTTGGATGGAGC CTCAC-3', FX2BR: 5'-TGCTTATGTCTGGGCAGTT-3'.

\section{Results}

Clinical presentaton

All 15 patients complained of prelingual hearing loss. Among them, ten children were found to have bilateral 
profound hearing loss by ABR, and six (DF001, DF003, DF005, DF008, DF010 and DF012) of them received cochlear implants in Xiangya Hospital. Five adult patients had bilateral severe hearing loss with a little hearing fluctuation but not progressive. High-resolution computed tomography (HRCT) of the temporal bone revealed that all the 15 patients had EVA-14 with bilateral EVA and one (DF010) unilateral. One patient (DF007) had goiter in the 2nd decade of her life.

\section{Mutation analysis}

The mutation screening in the 15 patients revealed no pathogenic alterations in GJB2 or in the mitochondrial 12s rRNA gene. SLC26A4 mutation study revealed 15 mutations in 11 of the 13 families examined, but no pathogenic mutations in families NDF3 and NDF9. Genotypes and phenotypes of the 15 patients are shown in Table 1. Among the alterations detected, IVS7-2A $>\mathrm{G}$ was most common, accounting for $22.3 \%(5 / 22)$ of the mutant alleles. None of these alterations was detected in 200 alleles of the normal Chinese controls, except one T410M mutant allele. Since hearing loss due to SLC26A4 mutations is autosomal recessive, if T410M is pathogenic, the carrier frequency for this mutation is $0.5 \%$ $(1 / 200)$. Both of the two intronic mutations, IVS7-2A $>G$ and IVS10-12T>A, were expected to lead to aberrant splicing, according to computer-assisted analysis on the database for Neural Network at Berkeley Drosophila Genome Project (http://www.fruitfly.org/seq_tools/splice.html). As all the 11 missense mutations are predicted to change amino acid residues at evolutionarily conserved domains of pendrin in human, mouse, and rat, they are likely true mutations rather than benign polymorphisms. Other base alterations were also detected in normal Chinese controls (Table 2), although they were hitherto undescribed.

\section{Discussion}

SLC26A4, encompasses 21 exons and contains a 2343-bp open reading frame. Its gene product, pendrin, is expressed in the inner ear, thyroid gland and kidney (Everett et al. 1997; Royaux et al. 2001). It was demonstrated that pendrin transports chloride and iodine, and mediates the exchange of chloride and formate (Scott et al. 2000; Royaux et al. 2001). There have been more than 100 different SLC26A4 mutations reported. The appearance of EVA by HRCT was demonstrated to be a reliable radiological sign for the diagnosis of PS (Phelps et al. 1998). These molecular and radiological findings indicated that PS and the hearing-loss with EVA fall into one clinical spectrum caused by SLC26A4 mutations, i.e., hearing loss with EVA with/without goiter (Tsukamoto et al. 2003).

Mutation analysis of SLC26A4 performed in 54 Chinese EVA families (including an area of Mainland China, Taiwan and Singapore) identified 23 different mutations (Yong et al. 2001; Dai et al. 2005; Wu et al. 2005; Yang et al. 2005; present study), viz., 14 missense mutations, two nonsense mutations, five intronic nucleotide changes and two deletions (Table 3). Seven of them were found in more

Table 1 Phenotype and genotype of 15 patients with hearing loss and EVA

\begin{tabular}{|c|c|c|c|c|c|c|c|c|}
\hline \multirow{2}{*}{$\begin{array}{l}\text { Subject } \\
\text { No. }\end{array}$} & \multirow[t]{2}{*}{ Family } & \multirow[t]{2}{*}{ Gender } & \multirow{2}{*}{$\begin{array}{l}\text { Age at } \\
\text { test (years) }\end{array}$} & \multirow[t]{2}{*}{ EVA } & \multirow[t]{2}{*}{ Goiter } & \multirow{2}{*}{$\begin{array}{l}\text { Level of hearing } \\
\text { impairment }\end{array}$} & \multicolumn{2}{|l|}{$S L C 26 A 4$ genotype } \\
\hline & & & & & & & Allele 1 & Allele 2 \\
\hline DF001 & NDF1 & M & 9 & B & - & $\mathrm{P}$ & IVS7-2A>G & $1975 \mathrm{G}>\mathrm{C} / \mathrm{V} 659 \mathrm{~L}$ \\
\hline DF002 & NDF1 & $\mathrm{F}$ & 6 & B & - & $\mathrm{P}$ & IVS7-2A>G & $1975 \mathrm{G}>\mathrm{C} / \mathrm{V} 659 \mathrm{~L}$ \\
\hline DF003 & NDF2 & $\mathrm{F}$ & 23 & B & - & $\mathrm{S}$ & $1174 \mathrm{~A}>\mathrm{T} / \mathrm{N} 392 \mathrm{Y}$ & $1343 \mathrm{C}>\mathrm{A} / \mathrm{S} 448 \mathrm{X}$ \\
\hline DF004 & NDF3 & M & 4 & B & - & $\mathrm{P}$ & wt & wt \\
\hline DF005 & NDF4 & M & 5 & B & - & $\mathrm{P}$ & $754 \mathrm{~T}>\mathrm{C} / \mathrm{S} 252 \mathrm{P}$ & $1229 \mathrm{C}>\mathrm{T} / \mathrm{T} 410 \mathrm{M}$ \\
\hline DF006 & NDF5 & M & 13 & $\mathrm{~B}$ & - & $\mathrm{S}$ & IVS7-2A $>\mathrm{G}$ & IVS7-2A>G \\
\hline DF007 & NDF6 & $\mathrm{F}$ & 23 & B & + & $\mathrm{S}$ & IVS4_IVS6del & IVS4_IVS6del \\
\hline DF008 & NDF7 & M & 2 & B & - & $\mathrm{P}$ & IVS7-2A>G & IVS10-12T>A \\
\hline DF009 & NDF7 & M & 7 & B & - & $\mathrm{P}$ & IVS7-2A>G & IVS10-12T>A \\
\hline DF010 & NDF8 & M & 2 & $\mathrm{R}$ & - & $\mathrm{P}$ & $1343 \mathrm{C}>\mathrm{T} / \mathrm{S} 448 \mathrm{~L}$ & $2168 \mathrm{~A}>\mathrm{G} / \mathrm{H} 723 \mathrm{R}$ \\
\hline DF011 & NDF9 & M & 7 & B & - & $\mathrm{P}$ & wt & wt \\
\hline DF012 & NDF10 & $\mathrm{F}$ & 10 & B & - & $\mathrm{P}$ & $2 \mathrm{~T}>\mathrm{C} / \mathrm{M} 1 \mathrm{~T}$ & $269 \mathrm{C}>\mathrm{T} / \mathrm{S} 90 \mathrm{~L}$ \\
\hline DF013 & NDF11 & $\mathrm{F}$ & 23 & B & - & $\mathrm{S}$ & $1226 \mathrm{G}>\mathrm{C} / \mathrm{R} 409 \mathrm{H}$ & $1229 \mathrm{C}>\mathrm{T} / \mathrm{T} 410 \mathrm{M}$ \\
\hline DF014 & NDF12 & M & 16 & B & - & $\mathrm{S}$ & $697 \mathrm{G}>\mathrm{C} / \mathrm{V} 233 \mathrm{~L}$ & $1229 \mathrm{C}>\mathrm{T} / \mathrm{T} 410 \mathrm{M}$ \\
\hline DF015 & NDF12 & $\mathrm{F}$ & 10 & B & - & $\mathrm{P}$ & IVS7-2A $>G$ & $2162 \mathrm{C}>\mathrm{T} / \mathrm{T} 721 \mathrm{M}$ \\
\hline
\end{tabular}

+ or - presence or absence, $M$ male, $F$ female, $B$ bilateral, $R$ right, $P$ profound, $S$ severe, $w t$ wild-type 
Table 2 Six variations in SLC26A4 observed in normal Chinese controls

\begin{tabular}{lllll}
\hline Nucleotide change & Amino acid change & Site & Effect & References \\
\hline 147G $>$ C & S49R & Exon 2 & Pathogenic & This study \\
IVS5-17 T $>$ C & - & Intron 5 & Polymorphism & This study \\
1229C $>$ T & T410M & Exon 10 & Pathogenic & This study; Coyle et al. (1998) \\
IVS11+47T $>$ C & - & Intron 11 & Polymorphism & This study \\
1905G $>$ A & G635 & Exon 17 & Polymorphism & This study \\
2009T $>$ C & V670A & Exon 17 & Pathogenic & This study \\
\hline
\end{tabular}

than one family. Among these recurrent mutations, IVS7$2 \mathrm{~A}>\mathrm{G}$ was reported to be most frequent, and accounted for $69.1 \%(76 / 110)$ of all mutant alleles in the Chinese, suggesting a founder effect of this intronic mutation (Park et al. 2003; Wu et al. 2005; Yang et al. 2005). In the present study, IVS7-2A $>\mathrm{G}$ was still the most frequent mutant allele, but accounted for only $22.3 \%(5 / 22)$ of all mutant alleles detected. Haplotype analysis also favored the derivation of IVS7-2A $>\mathrm{G}$ from a common ancestor (data not shown). Another mutation, H723R, the predominant mutation among the Japanese, accounting for 53\% of mutant alleles (Tsukamoto et al. 2003), was rarely seen among the Mainland Chinese. Only one H723R mutant allele was detected in our 15 EVA patients (1/22 alleles), and none in 100 normal Chinese controls (0/200 alleles) in this study. These findings suggest a distinct mutation spectrum in Chinese patients, since, apart from the aforesaid, 13 of 23 mutations reported in the Chinese have never been described in other ethnic groups (Table 3), whereas only five mutations (M1T, R409H, T410M, T721M, H723R) have been described in populations except for Asians (Coyle et al. 1998; Van Hauwe et al. 1998; Usami et al. 1999; Prasad et al. 2004; Shears et al. 2004).

In the present study, we did not find any SLC26A4 mutations in two of 13 families with EVA. This may be explained by a possible occurrence of EVA due to other
Table 3 SLC26A4 gene mutations identified in the Chinese
${ }^{a}$ Mutations were observed only in the Chinese, and those underlined are novel mutations observed in this study

\begin{tabular}{|c|c|c|c|}
\hline $\begin{array}{l}\text { Mutation } \\
\text { site }\end{array}$ & Mutation & $\begin{array}{l}\text { No. of } \\
\text { mutations } \\
\text { detected }\end{array}$ & References \\
\hline 2 & M1T & 1 & This study \\
\hline 3 & S90L & 1 & This study \\
\hline 3 & $\mathrm{~K} 77 \mathrm{I}^{\mathrm{a}}$ & 1 & Wu et al. (2005) \\
\hline 5,6 & $\underline{\text { IVS4_IVS6del1.8kb }}^{\mathrm{a}}$ & 2 & This study \\
\hline 6 & ${\underline{\mathrm{V} 233 \mathrm{~L}^{\mathrm{a}}}}$ & 1 & This study \\
\hline 6 & $\mathrm{~S} 252 \mathrm{P}^{\mathrm{a}}$ & 2 & This study; Park et al. (2003) \\
\hline 7 & G316X $\mathrm{X}^{\mathrm{a}}$ & 1 & Dai et al. (2005) \\
\hline IVS 7 & IVS7-2A>G & 76 & $\begin{array}{l}\text { This study; Dai et al. (2005); Hu et al. (2005b); Park et al. } \\
\text { (2003); Wu et al. (2005); Yong et al. (2001) }\end{array}$ \\
\hline 9 & A372V & 1 & Wu et al. (2005) \\
\hline 10 & $\mathrm{E} 387 \mathrm{~V}^{\mathrm{a}}$ & 1 & Wu et al. (2005) \\
\hline 10 & N392Y & 3 & This study; Hu et al. (2005a); Park et al. (2003) \\
\hline 10 & S394del ${ }^{\mathrm{a}}$ & 1 & Yong et al. (2001) \\
\hline 10 & R409H & 1 & This study \\
\hline 10 & $\mathrm{~T} 410 \mathrm{M}$ & 4 & This study; Wu et al. (2005) \\
\hline IVS 10 & ${\underline{I V S} 10-12 \mathrm{~T}>\mathrm{A}^{\mathrm{a}}}$ & 1 & This study \\
\hline 12 & $\mathrm{~S} 448 \mathrm{X}^{\mathrm{a}}$ & 1 & This study; Hu et al. (2005a) \\
\hline 12 & $\mathrm{~S} 448 \mathrm{~L}^{\mathrm{a}}$ & 2 & This study; Wu et al. (2005) \\
\hline IVS 13 & IVS13+9C $>\mathrm{G}^{\mathrm{a}}$ & 1 & Yong et al. (2001) \\
\hline IVS 15 & IVS15+5G $>A$ & 2 & Yang et al. (2005) \\
\hline IVS 16 & IVS16-6G $>A^{a}$ & 1 & Yang et al. (2005) \\
\hline 17 & ${\underline{\mathrm{V}} 659 \mathrm{~L}^{\mathrm{a}}}$ & 1 & This study \\
\hline 19 & $\mathrm{~T} 721 \mathrm{M}$ & 2 & This study; Wu et al. (2005) \\
\hline 19 & $\mathrm{H} 723 \mathrm{R}$ & 3 & This study; Yong et al. (2001) \\
\hline
\end{tabular}


unknown aetiology. Alternatively, SLC26A4 mutations may have lain in activate cryptic splice sites in introns or in the promoter region, which was not analyzed in this study. A finding in the murine that Foxil is a gene regulator of pendrin suggests that human FOXII could be another gene causative for human hearing loss with EVA (Hulander et al. 2003). Although we performed mutation analysis of FOXII in all the probands with EVA, no pathogenic mutation was detected (data not shown).

In summary, we have reported on a mutation screening of SLC26A4 in 13 families with hearing loss and EVA from Central Southern China. Consequently, a spectrum of SLC26A4 mutations was different from that in the previously reported Chinese cohort in Taiwan and Singapore (Wu et al. 2005; Yang et al. 2005), suggesting the presence of allelic heterogeneity among Chinese patients with hearing-loss and EVA. Further studies of a larger cohort are needed to support this assumption.

Acknowledgments We thank the families who participated in this study. This work was supported by the research grants from National Natural Science Foundation of China $(30270735,30571201)$ and from “'863'” Program (2002BA711A07).

\section{References}

Campbell C, Cucci RA, Prasad S, Green GE, Edeal JB, Galer CE, Karniski LP, Sheffield VC, Smith RJ (2001) Pendred syndrome, DFNB4, and PDS/SLC26A4 identification of eight novel mutations and possible genotype-phenotype correlations. Hum Mutat 17:403-411

Coyle B, Reardon W, Herbrick JA, Tsui LC, Gausden E, Lee J, Coffey R, Grueters A, Grossman4 A, Phelps PD, Luxon L, Kendall-Taylor P, SchererSW, Trembath RC (1998) Molecular analysis of the PDS gene in Pendred syndrome. Hum Mol Genet 7:1105-1112

Dai P, Yu F, Kang DY, Zhang X, Liu X, Mi WZ, Cao JY, Yuan HJ, Yang WY, Wu BL, Han DY (2005) Diagnostic methods and clinic application for mtDNA A1555G and GJB2 and SLC26A4 genes in deaf patients. Zhonghua Er Bi Yan Hou Tou Jing Wai Ke Za Zhi 40:769-773

Everett LA, Glaser B, Beck JC, Idol JR, Buchs A, Heyman M, Adawi F, Hazani E, Nassir E, Baxevanis AD, Sheffield VC, Green ED (1997) Pendred syndrome is caused by mutations in a putative sulphate transporter gene (PDS). Nat Genet 17:411-422

Fischel-Ghodsian N (1999) Mitochondrial deafness mutations reviewed. Hum Mutat 13:261-270

Guan MX (2004) Molecular pathogenetic mechanism of maternally inherited deafness. Ann N Y Acad Sci 1011:259-271

Hu H, Liang DS, Wu LQ, Feng Y, Cai F, Xia K, Pan Q, Long ZG, Dai HP, Xia JH (2005a) Molecular analysis of SLC26A4 gene in a Chinese deafness family. Zhonghua Yi Xue Yi Chuan Xue Za Zhi 22:376-379

Hu H, Wu LQ, Liang DS, Feng Y, Cai F, Xia K, Pan Q, Long ZG, Dai HP, Xia JH (2005b) Prenatal diagnosis of prelingual deafness by determination of SLC26A4 gene mutation. Zhonghua Fu Chan Ke Za Zhi 40:591-594

Hulander M, Kiernan AE, Blomqvist SR, Carlsson P, Samuelsson EJ, Johansson BR, Steel KP, Enerback S (2003) Lack of pendrin expression leads to deafness and expansion of the endolymphatic compartment in inner ears of Foxi1 null mutant mice. Development 130:2013-2025

Kenneson A, Van Naarden Braun K, Boyle C (2002) GJB2 (connexin 26) variants and nonsyndromic sensorineural hearing loss: a HuGE review. Genet Med 4:258-274

Li R, Greinwald JH Jr, Yang L, Choo DI, Wenstrup DI, Guan MX (2004) Molecular analysis of the mitochondrial 12S rRNA and tRNASer(UCN) genes in paediatric subjects with non-syndromic hearing loss. J Med Genet 41:615-620

Li XC, Everett LA, Lalwani AK, Desmukh D, Friedman TB, Green ED, Wilcox ER (1998) A mutation in PDS causes nonsyndromic recessive deafness. Nat Genet 18:215-217

Li Z, Li R, Chen J, Liao Z, Zhu Y, Qian Y, Xiong S, Heman-Ackah S, Wu J, Choo DI, Guan MX (2005) Mutational analysis of the mitochondrial 12S rRNA gene in Chinese pediatric subjects with aminoglycoside-induced and non-syndromic hearing loss. Hum Genet 117:9-15

Morton NE (1991) Genetic epidemiology of hearing impairment. Ann N Y Acad Sci 630:16-31

Park HJ, Shaukat S, Liu XZ, Hahn SH, Naz S, Ghosh M, Kim HN, Moon SK, Abe S, Tukamoto K, Riazuddin S, Kabra M, Erdenetungalag R, Radnaabazar J, Khan S, Pandya A, Usami SI, Nance WE, Wilcox ER, Riazuddin S, Griffith AJ (2003) Origins and frequencies of SLC26A4 (PDS) mutations in east and south Asians: global implications for the epidemiology of deafness. J Med Genet 40:242-248

Phelps PD, Coffey RA, Trembath RC, Luxon LM, Grossman AB, Britton KE, Kendall-Taylor P, Graham JM, Cadge BC, Stephens SG, Pembrey ME, Reardon W (1998) Radiological malformations of the ear in Pendred syndrome. Clin Radiol 53:268-273

Prasad S, Kolln KA, Cucci RA, Trembath RC, Van Camp G, Smith RJ (2004) Pendred syndrome and DFNB4-mutation screening of SLC26A4 by denaturing high-performance liquid chromatography and the identification of eleven novel mutations. Am J Med Genet 124A:1-9

Reardon W, Coffey R, Chowdhury T, Grossman A, Jan H, Britton K, Kendall-Taylor P, Trembath R (1999) Prevalence, age of onset, and natural history of thyroid disease in Pendred syndrome. $\mathrm{J}$ Med Genet 36:595-598

Royaux IE, Wall SM, Karniski LP, Everett LA, Suzuki K, Knepper MA, Green ED (2001) Pendrin, encoded by the Pendred syndrome gene, resides in the apical region of renal intercalated cells and mediates bicarbonate secretion. Proc Natl Acad Sci USA 98:4221-4226

Scott DA, Karniski LP (2000) Human pendrin expressed in Xenopus laevis oocytes mediates chloride/formate exchange. Am J Physiol Cell Physiol 278:C207-C211

Shears D, Conlon H, Murakami T, Fukai K, Alles R, Trembath R, Bitner-Glindzicz M (2004) Molecular heterogeneity in two families with auditory pigmentary syndromes: the role of neuroimaging and genetic analysis in deafness. Clin Genet 65:384-389

Tsukamoto K, Suzuki H, Harada D, Namba A, Abe S, Usami S (2003) Distribution and frequencies of PDS (SLC26A4) mutations in Pendred syndrome and nonsyndromic hearing loss associated with enlarged vestibular aqueduct: a unique spectrum of mutations in Japanese. Eur J Hum Genet 11:916-922

Usami S, Abe S, Weston MD, Shinkawa H, Van Camp G, Kimberling WJ (1999) Non-syndromic hearing loss associated with enlarged vestibular aqueduct is caused by PDS mutations. Hum Genet 104:188-192

Van Camp GSR (2006) Hereditary hearing loss homepage (http:// www.dnalab-www.uia.ac.be/dnalab/hhh/)

Van Hauwe P, Everett LA, Coucke P, Scott DA, Kraft ML, RisStalpers C, Bolder C, Otten B, de Vijlder JJ, Dietrich NL, Ramesh 
A, Srisailapathy SC, Parving A, Cremers CW, Willems PJ, Smith RJ, Green ED, Van Camp G (1998) Two frequent missense mutations in Pendred syndrome. Hum Mol Genet 7:1099-1104

Wu CC, Yeh TH, Chen PJ, Hsu CJ (2005) Prevalent SLC26A4 mutations in patients with enlarged vestibular aqueduct and/or Mondini dysplasia: a unique spectrum of mutations in Taiwan, including a frequent founder mutation. Laryngoscope 115:10601064
Yang JJ, Tsai CC, Hsu HM, Shiao JY, Su CC, Li SY (2005) Hearing loss associated with enlarged vestibular aqueduct and Mondini dysplasia is caused by splice-site mutation in the PDS gene. Hear Res 199:22-30

Yong AM, Goh SS, Zhao Y, Eng PH, Koh LK, Khoo DH (2001) Two Chinese families with Pendred's syndrome-radiological imaging of the ear and molecular analysis of the pendrin gene. J Clin Endocrinol Metab 86:3907-3911 